\title{
Pancreaticoduodenal secretions and the genesis of gastric stump carcinoma in the rat
}

\author{
R C MASON, P R TAYLOR, M I FILIPE, AND I MCCOLL \\ From the Departments of Surgery and Histopathology, UMDS Guy's and St Thomas', Guy's Hospital, London
}

SUMmaRY This study was designed to investigate the role of duodenogastric reflux in the genesis of gastric stump carcinoma in the rat. Carcinoma was not detected in any of the 11 control animals and in only one animal with a Roux diversion. In contrast seven of 12 animals with duodenogastric reflux developed carcinoma $(p<0 \cdot 01$ and $p<0 \cdot 05$ respectively). In order to determine which fraction of the reflux was implicated in the malignant process, animals with reflux of bile alone or pancreaticoduodenal secretions alone were studied. No carcinomas were found in 11 animals with bile reflux alone, but carcinoma was detected in 10 of 14 animals with reflux of pancreaticoduodenal secretions $(p<0 \cdot 01)$. The findings confirm that duodenogastric reflux is an important factor in the malignant process, and imply that the pancreaticoduodenal component, not bile is responsible.

It is now established that previous gastric surgery for benign disease increases the risk of development of gastric stump carcinoma.' Duodenogastric reflux which is obligatory after operations in which the pylorus is excised or bypassed has been implicated in the malignant process.' Which fraction of the reflux is responsible is not known.

We have investigated this question in an animal model which does not require the administration of exogenous carcinogens to produce malignant change. ${ }^{2}$ Initial results have confirmed the suitability of the model and suggest that pancreaticoduodenal secretions and not bile are implicated. ${ }^{3}$ In this study we have increased the number of animals studied in order to prove which fraction of the reflux is involved in the malignant process and added an extra control group to determine whether resection alone without reflux is a major contributory factor.

\section{Methods}

ANIMALS

Male Wistar rats (250-270 g) were anaesthetised with $4 \%$ halothane in oxygen. The five operative procedures outlined in Figure 1 were undertaken. The same suture (5/0 Ethibond - Ethicon, Edinburgh)

Address for correspondence: Mr R C Mason, Dept of Surgery, Guy`s Hospital. London SE1 9RT.

Received for publication 10 December 1987. was used in all cases. Control animals received a $7 \mathrm{~mm}$ anterior gastrotomy. All the other animals had a two-third resection of the glandular stomach with anastomosis to proximal jejunum designed to produce (1) no reflux - Roux diversion, (2) reflux of bile alone, (3) reflux of pancreaticoduodenal secretions alone, or (4) combined reflux of bile and pancreaticoduodenal secretions. On recovery, animals were maintained under identical conditions with free access to water and standard rat chow.

After nine months all animals were reanaesthetised and laparotomy carried out. Through a small gastrotomy, $5 \mathrm{ml}$ normal saline was instilled. This was assayed for total bile acid concentration using the method of Brussgaard ${ }^{4}$ to act as a biochemical check of the pattern of reflux achieved. The stomach was then examined to exclude fistulae before removal and fixation in formal saline. The animals were killed by exsanguination while still under anaesthesia.

Samples of anterior wall of the stomach including suture lines, posterior wall, and lesser curve were removed for histological examination. They were processed for wax embedding, sectioned and stained with haematoxalin and eosin. All sections were reviewed blind by a consultant histopathologist (MIF) who was unaware of the operation carried out. Carcinoma was diagnosed using cytological criteria and intramural invasion to distinguish it from tumour like lesions such as adenocystic proliferation of 

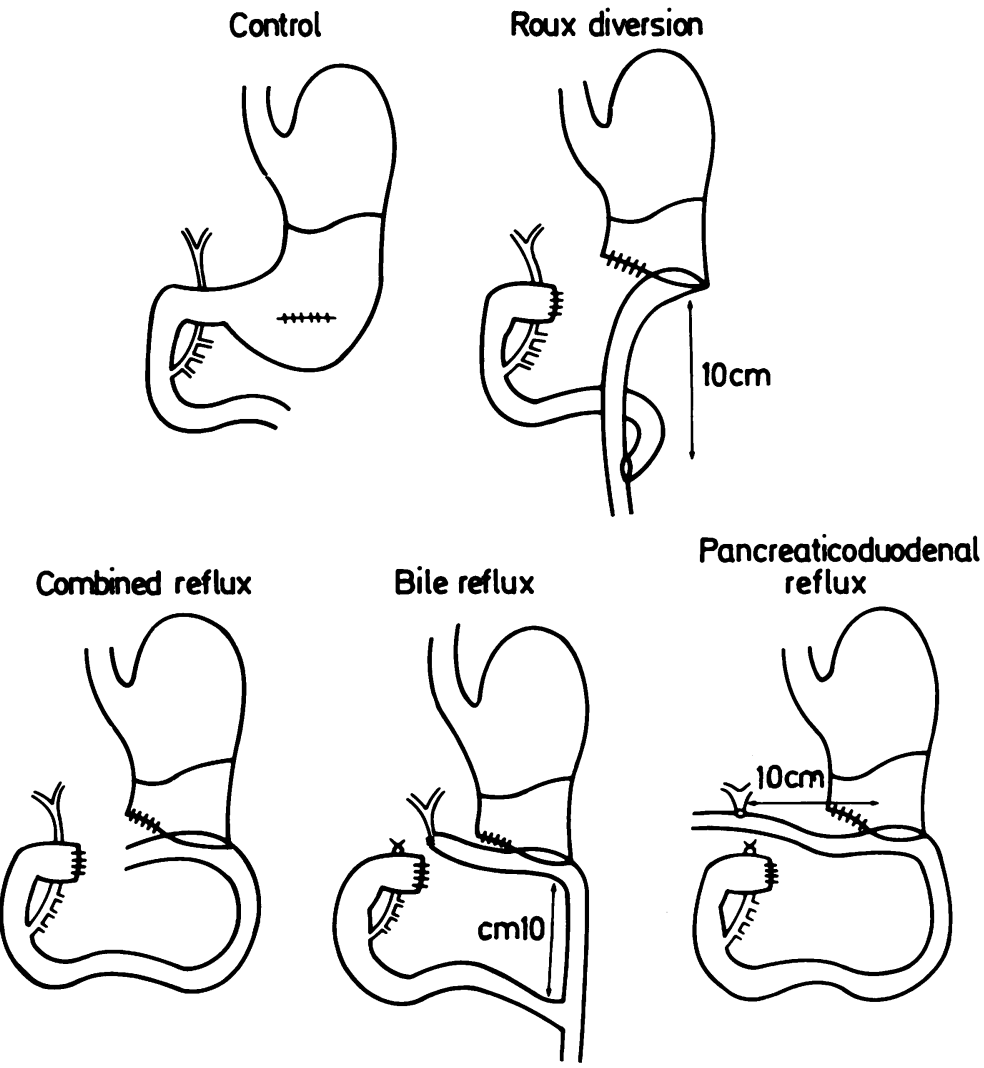

Fig. 1 Operations undertaken in the five groups of animals. All surgery was done on the glandular stomach. glands. ${ }^{5}$ The tumours were characterised according to their gross appearance (polypoid or ulcerating), infiltrative growth pattern (nodular expanding or diffuse spread) and histological features (mucoid or tubular nonsecreting). Invasion into adjacent organs and lymph nodes were also noted.

\section{Results}

The results are shown in Table 1. Two animals subjected to Roux diversion were found to have developed fistulae between the duodenal stump and the lesser curve of stomach (Fig. 2). These animals

Table 1 Incidence of carcinoma in the five groups of animals

\begin{tabular}{lll}
\hline Type of reflux & Animals $(n)$ & With carcinoma $(n)$ \\
\hline Controls (none) & 11 & 0 \\
Roux diversion (nonc) & 12 & $1(8 \%)$ \\
Bile & 11 & 0 \\
Pancreaticoduodenal & 14 & $10(71 \%)$ \\
Combined & 12 & $7(58 \%)$ \\
Fistulac & 2 & 2 \\
\hline
\end{tabular}

have been considered separately. The discrepancy in numbers is the result of animals dying before nine months. With two exceptions these occurred within one month of surgery and were the result of respiratory complications. Two animals in the bile reflux group died at four and five months after surgery because of liver abscess.

The levels of bile acids in the stomachs of the five groups of animals are shown in Figure 3. Those animals with reflux of bile either alone or in combination with pancreaticoduodenal secretions had significantly higher levels than in the other groups without reflux (controls and Roux diversions) or animals with pancreaticoduodenal reflux alone $(p<0 \cdot 01$ Wilcoxon's rank-sum test). This difference being in the order of 10 -fold. It is of interest to note that the level of bile acids in the two animals with fistulae were similar to those found in animals with combined reflux.

The incidence of carcinoma in the five groups of animals is shown in Table 1 . No carcinomas were found in the control or bile reflux groups, and only one was found in animals with a Roux diversion. In contrast, carcinoma was detected in seven of 12 animals with combined reflux and 10 of 14 animals 


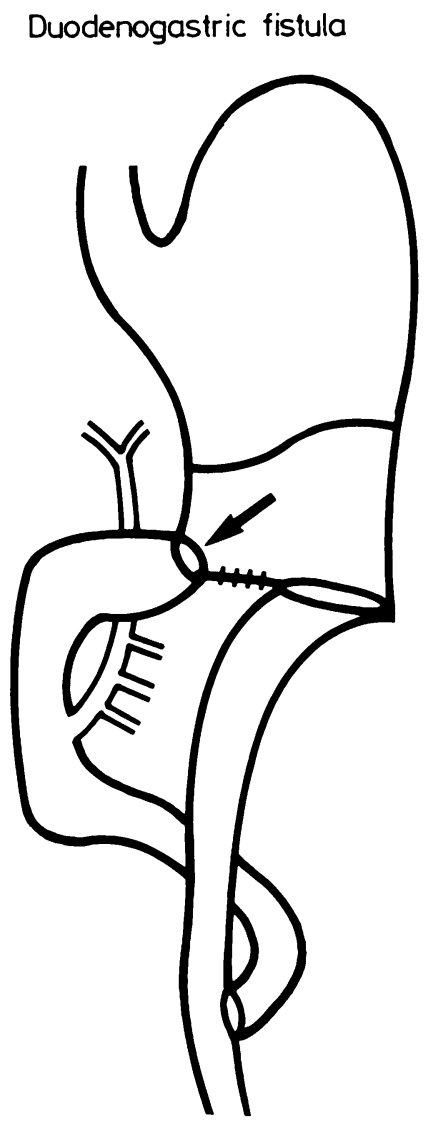

Fig. 2 Diagramatic representation of the fistulae found in two animals with Roux diversion. Fistula between the stomach and duodenum is arrowed.

with reflux of pancreaticoduodenal secretions alone.

The association between reflux of pancreaticoduodenal secretions alone or in combination with bile is statistically significant on $\chi^{2}$ testing with Yates correction factor for small numbers (Table 2). Both animals with fistulae had developed carcinoma.

None of the tumours were polypoid, and the

Table 2 Statistical analysis of the incidence of carcinoma

\begin{tabular}{|c|c|c|c|c|}
\hline & Control & $\begin{array}{l}\text { Roux } \\
\text { division }\end{array}$ & $\begin{array}{l}\text { Bile } \\
\text { reflux }\end{array}$ & $\begin{array}{l}\text { Pancduod } \\
\text { reflux }\end{array}$ \\
\hline $\begin{array}{l}\text { Roux } \\
\text { division }\end{array}$ & $\begin{array}{c}\chi^{2}=0 \\
\mathrm{~ns}\end{array}$ & & & \\
\hline $\begin{array}{l}\text { Bile } \\
\text { reflux }\end{array}$ & $\begin{array}{c}\chi^{2}=0 \\
\mathrm{~ns}\end{array}$ & $\begin{array}{c}\chi^{2}=0 \\
n s\end{array}$ & & \\
\hline $\begin{array}{l}\text { Pancduod } \\
\text { reflux }\end{array}$ & $\begin{array}{c}\chi^{2}=10 \cdot 3 \\
p<0 \cdot() 1\end{array}$ & $\begin{array}{c}\chi^{2}=8 \cdot 1 \\
p<0 \cdot(01\end{array}$ & $\begin{array}{c}\chi^{2}=10 \cdot 3 \\
p<0 \cdot(01\end{array}$ & \\
\hline $\begin{array}{l}\text { Combined } \\
\text { reflux }\end{array}$ & $\begin{aligned} \chi^{2} & =6.7 \\
p & <(0.01\end{aligned}$ & $\begin{aligned} \chi^{2} & =4.7 \\
p & <0.05\end{aligned}$ & $\begin{aligned} \chi^{2} & =6.7 \\
& p<0.01\end{aligned}$ & $\begin{array}{c}\chi^{2}=0 \cdot 1 \\
\text { ns }\end{array}$ \\
\hline
\end{tabular}

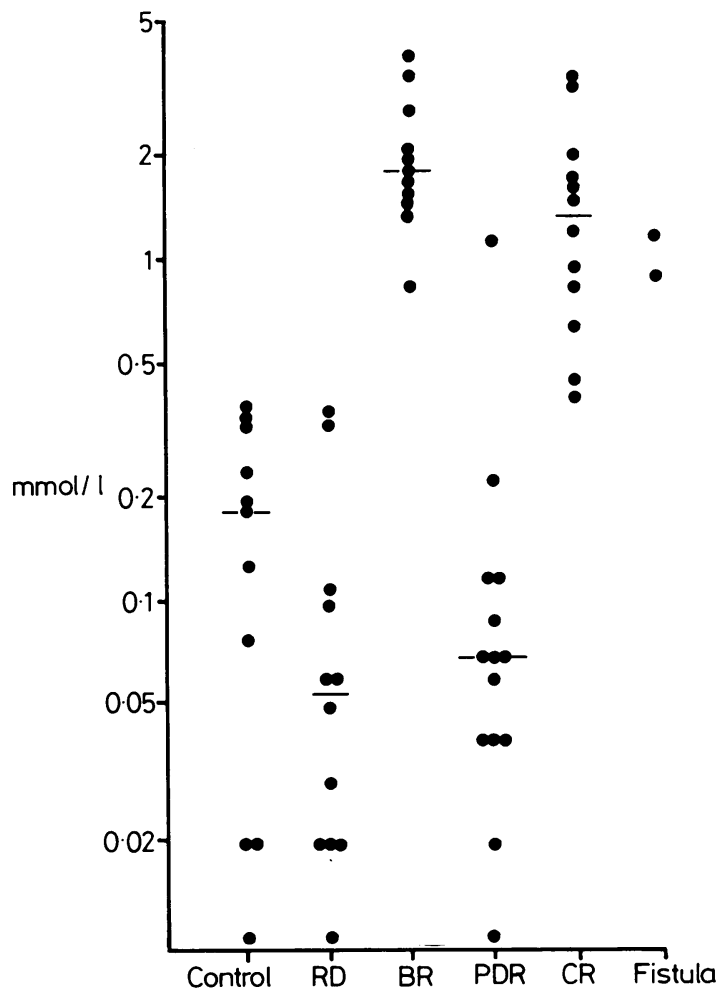

Fig. 3 Concentration of bile acids in gastric washings from the five groups of animals. Horizontal lines indicate median values. $R D=$ Roux diversion, $B R=$ bile reflux alone, $P D R=$ pancreaticoduodenal reflux alone, and $C R=$ combined reflux of bile and pancreaticoduodenal secretions.

majority secreted large amounts of mucus (13/20) (Fig. 4), showing an expanded type of growth rather than diffuse spread. Invasion into the adjacent organs was uncommon, the liver being involved in three cases and lymph nodes in one.

\section{Discussion}

The observation that reflux of bile and pancreaticoduodenal secretions together will produce carcinoma confirms the findings of Langhans et al..$^{2}$ They also found that fistulae between the duodenum and lesser curve of stomach produced carcinoma. The finding of a carcinoma in an animal with a Roux diversion, in which assay of bile acids in the stomach showed a level within the range found in controls indicating that duodenogastric reflux was not occurring, has only been described before in animals given MNNG." This suggests that duodenogastric reflux is not the sole factor in the genesis of gastric stump carcinoma in these animals, although it undoubtably promotes 


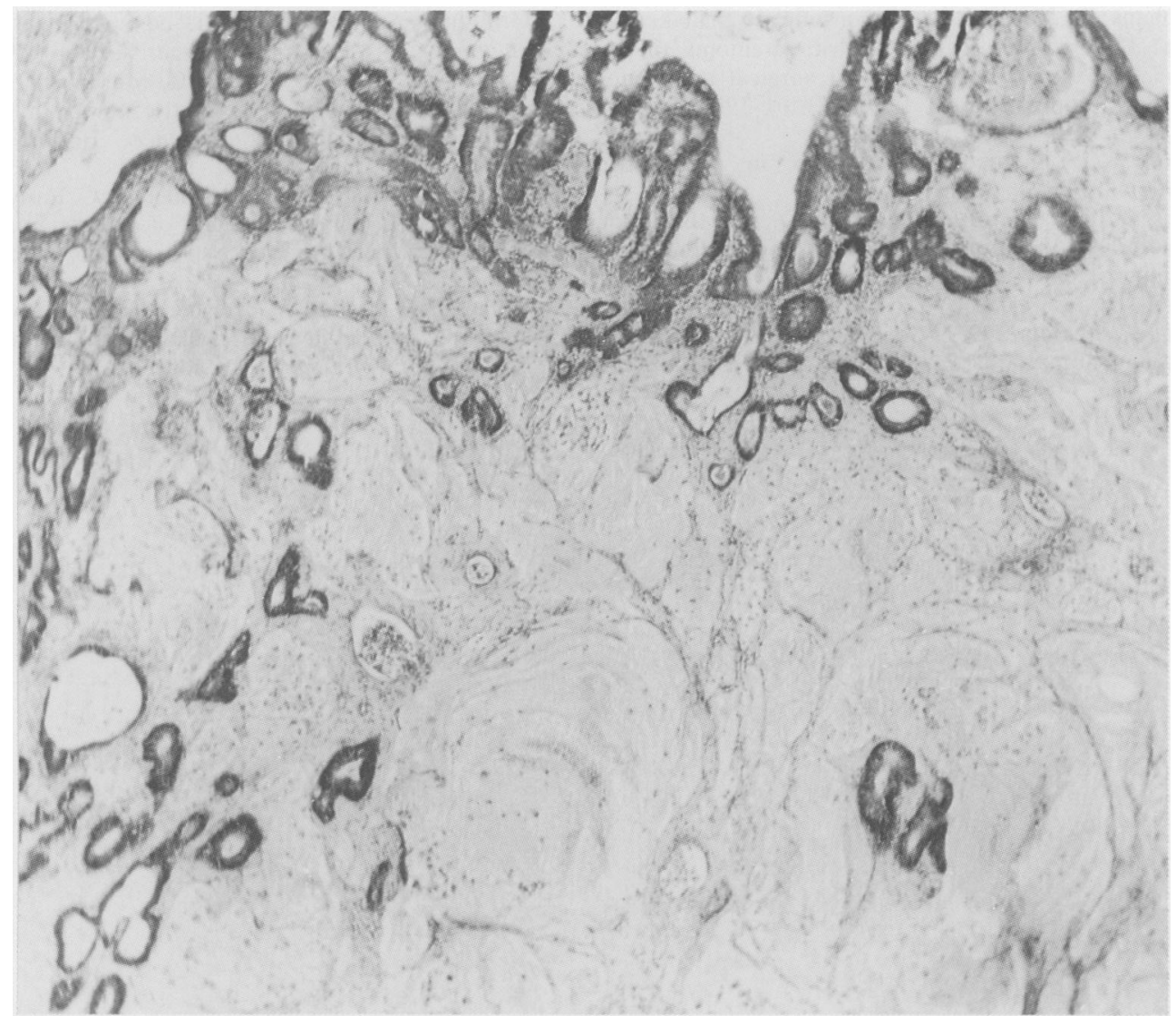

Fig. 4 Mucus secreting adenocarcinoma in the rat after gastric surgery to produce reflux of pancreaticoduodenal secretions alone. (Haematoxylin and eosin.)

carcinogenesis. It is possible that non-absorbable sutures perpetuate the hyperplastic reaction to surgical trauma enabling other factors to affect this unstable mucosa.

Diagnosis of carcinoma in the presence of sutures is also very difficult.? Islands of cells can be carried under the mucosa by sutures and mimic invasion. We have therefore attached most importance in the diagnosis of carcinoma to cytological criteria. The finding of carcinoma in animals with reflux of pancreaticoduodenal secretions alone or in combination with bile confirms our earlier work ${ }^{3}$ which suggested this association. In the past, bile has been implicated as the causative agent. ${ }^{\circ}$ This is largely a problem of nomenclature as the term 'bile reflux' ignores the pancreaticoduodenal component. To avoid this confusion the term duodenogastric reflux should be used.

It is unlikely that pancreaticoduodenal secretions are carcinogenic, rather they act as promotors of other carcinogens or perpetuate the hyperplastic response to a chronic irritant. Extrapolation of findings in animals to the human situation should be done with extreme caution. These findings do support, however, the concept that previous gastric surgery for benign disease increases the risk of malignant change. They may also shed light on the possible mechanisms of development of this form of carcinoma.

We should like to thank the Special Trustees of Guy's Hospital for the award of a grant in the name of the late Mr and Mrs Leak to undertake this study, and Dr G Murphy of the Dept of Gastroenterology for measuring bile acid concentrations of gastric washings.

\section{References}

1 Caygill CPJ, Hill MJ, Kirkham JS, Northfield TC. Mortality from gastric cancer following gastric surgery for peptic ulcer. Lancet 1986; ii: 929-31. 
2 Langhans P, Heger RA, Hohenstein J, Schlake W, Bunte $H$. Operation sequal gastric carcinoma of the stomach. Experimental studies of surgical techniques with or without resection. World J Surg 1981; 5: 595605.

3 Mason RC. Duodenogastric reflux in rat gastric carcinoma. BrJ Surg 1986; 73: 801-3.

4 Bruusgaard A. Quantitative determination of the major 3a hydroxy bile acids in biological material after thin layer chromatographic separation. Clin Chim Acta 1970; 28: 495-504.

5 Schlake W, Nomura K. Histogenesis of carcinoma in the glandular stomach of the rat after B I resection. In:
Grundmann E, Kirsten WH, eds. Current topics in pathology. Vol 67. Berlin: Springer Verlag, 1979: 2-67.

6 Dahm K, Werner B, Eichen R, Mitschke H. Experimental gastric cancer in the gastric stump. In: Herfarth $\mathrm{CH}$, Schlag P, eds. Gastric cancer. Berlin: Springer Verlag, 1979: 45-59.

7 Kunze E, Schauer A, Eder M, Seefeldt C. Early sequential lesions during development of experimental gastric cancer with special reference to dysplasias. J Cancer Res Clin Oncol 1979: 95: 247-64.

8 Domellof L, Reddy BD, Weisberger JD. Microflora and deconjugation of bile acids in alkaline reflux after partial gastrectomy. Am J Surg 1980; 140: 291-6. 